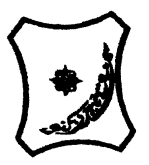

Bayero Journal of Pure and Applied Sciences, 12(1):112 - 116

ISSN $2006-6996$

\title{
COMMUNITY PHARMACISTS' PERCEPTIONS AND KNOWLEDGE OF COMPLEMENTARY AND ALTERNATIVE MEDICINES (CAM) IN KADUNA, NIGERIA
}

\author{
${ }^{1}$ Ma'aji, H.U., ${ }^{1}$ Auwal, F.I., ${ }^{1}$ Laban, S., Abdu-Aguye, S.N1 . and ${ }^{2}$ Amorha, K.C. \\ ${ }^{1}$ Department of Clinical Pharmacy and Pharmacy Practice, Ahmadu Bello University, Zaria. \\ 2Department of Clinical Pharmacy and Pharmacy Management, University of Nigeria, Nsukka. \\ Correspondence Author: fatyauwal03@gmail.com +2348068048681
}

\begin{abstract}
Herbal supplements or "botanicals," are a type of complementary and alternative medicine (CAM) made from one or more plants, and are thought to be useful in treating diseases or maintaining health. These supplements are usually found in pharmacies, and continue to gain popularity among consumers today. The aim of this study was to assess the perceptions and knowledge of community pharmacists practicing in Zaria \& Kaduna metropolis on herbal supplements. A cross-sectional survey was carried out from July to October 2016 on pharmacists working in 82 randomly selected community pharmacies. A structured questionnaire containing four sections and 45 questions was used to collect data from respondents on their demographic characteristics, personal experiences with herbal supplements, knowledge of selected herbal supplements and general perceptions of herbal supplements. Data collected was coded and analyzed using SPSS version 20, and descriptive statistics used to report results. While 120 questionnaires were distributed, only 99 were eventually retrieved. Majority of the respondents were male (80\%), and had BPharm as their highest educational qualification (97\%). Most of the respondents reported having used herbal supplements before (92\%) and up to $71 \%$ had used these supplements within the last 12 months. Many of the respondents (70\%) had poor knowledge regarding the indications, safety and interactions associated with the use of selected herbal supplements. Over $90 \%$ of them agreed that herbal supplements are beneficial, and should be integrated into conventional clinical care, however less than half of them believed that these supplements were safe and had fewer side effects than conventional medicines. Community pharmacists in Kaduna have poor knowledge but largely positive perceptions of herbal supplements.
\end{abstract}

Keywords: CAM, Knowledge, Perceptions, Community Pharmacists, Herbal Supplements, Nigeria

\section{INTRODUCTION}

Complementary and alternative medicines (CAMs) are substances or procedures that are believed to have some therapeutic benefits. They encompass 'herbal medicines, vitamin and mineral supplements, other nutritional supplements, traditional medicines such as Ayurvedic medicines and traditional Chinese medicines (TCM), homeopathic medicines and aromatherapy oils'(Bushett et al., 2011)

Herbal medicinal products or supplements also called "botanicals", are a type of CAM. They are made from one or more plants, and are thought to be useful in treating or managing disease conditions or maintaining health (Terrie, 2012). The use of these supplements has increased tremendously over the past three decades, and it is estimated that around $50-80 \%$ of people worldwide use them regularly (Ekor, 2013;
Wegener, 2017). Although the efficacy of some of these herbal supplements have been clearly established, many of them remain untested (Ekor, 2013). In addition, they are generally not subjected (by national or international drug regulatory bodies) to the same scientific scrutiny and strict regulation as conventional medications. Consequently, safety continues to be an important issue with the use of these medicines (Ekor, 2013).

Majority of herbal supplements sold worldwide are purchased at community pharmacies and other drug retailing outlets as non-prescription medication (Oshikoya et al., 2013; Ogbogu and Necyk, 2016). Thus, pharmacists are the "frontline" health professionals involved in ensuring the safe and rational use of these agents (Ogbogu and Necyk, 2016). 
Special Conference Edition, November, 2019

It is therefore important to study pharmacist knowledge of, attitudes towards use and perceptions of these supplements, in order to optimize their safe use. In addition, while a few studies within the country have studied community pharmacists' knowledge and recommendation patterns of these agents (Oshikoya et al., 2013; Amorha et al., 2017), these studies have all been carried out within the Southern part of the country (Lagos in particular). Therefore, the aim of this study was to assess the perceptions and knowledge of herbal supplements in community pharmacists practicing within Kaduna state

\section{MATERIALS AND METHODS}

\section{Study site}

The study was carried out in Kaduna state-the fourth largest state-by land mass- in Nigeria. Kaduna state contains three major urban areas: Kaduna metropolis, Kafanchan and Zaria (Auwal et al., 2019). Because majority of all the registered pharmacies in the state are located within two of these areas- Kaduna metropolis and Zaria (Auwal et al., 2019) this study was carried out in those areas.

\section{Study design and Data Collection Instrument}

A cross-sectional survey of 82 randomly selected community pharmacies located within Kaduna Metropolis and Zaria town was carried out from July to October, 2016. All pharmacists working in these pharmacies were eligible to participate if they were willing. A questionnaire was used to collect data. This questionnaire-which was adapted from an earlier study (Amorha et al., 2017), was structured into four sections and contained 45 questions. The first section containing seven items collected information on the socio-demographic characteristics of respondents. The second section explored their use of herbal supplements (5 questions). Section three with 21 questions assessed their knowledge of selected popular herbal supplements (Echinacea, Gingko biloba, Garlic, Ginseng, Valerian and St John's Wort) in terms of indication, dosage, side effects and interaction with other drugs. These questions were in multiple choice format with only one correct answer among the four options provided, one option of which was always "I don't know'. Finally the last section collected data on their perceptions towards herbal supplements use using a five point Likert scale, as well as their sources of information on these agents.

\section{Data Collection}

The randomly selected pharmacies were visited and the pharmacist(s) in each premise approached and informed about the objectives of the study. Afterwards, their consent was sought, and those who agreed to participate were given the questionnaire to fill. The researcher allowed a period of five days to elapse before returning to the pharmacies to collect completed questionnaires.

\section{Data Analysis}

Data collected was coded and analyzed using SPSS version 20 software and descriptive statistics (frequencies and percentages) used to report the data obtained.

To assess knowledge, each correctly answered question was scored one mark, while wrong answers and "I don't know" responses were scored zero points. A total score (out of the maximum achievable 21 points) was calculated for each respondent. If a respondent's score fell within the range of $0-7$, he/she was rated as having poor knowledge. If the score fell within the 8-14 range, he/she was rated as having fair knowledge. Any score higher than the 0-14 range, was rated as good knowledge.

\section{RESULTS}

While 120 questionnaires were distributed to pharmacists working in the visited community pharmacies, only 99 were retrieved producing an $82.5 \%$ response rate.

Socio-demographic Characteristics of Study Respondents

Majority of respondents were male $(80 \%)$, and aged between $20-40$ years (82\%). In addition, most of them $(97 \%)$ had the Bachelor of Pharmacy Degree (BPharm) as their highest educational qualification (Table 1 ).

\section{Table 1: Socio-Demographic Characteristics of Respondents $(n=99)$}

\begin{tabular}{llll}
\hline Characteristic & & $\mathbf{n}$ & Percentage (\%) \\
\hline Gender & Male & 79 & 80 \\
& Female & 20 & 20 \\
\hline Age (years) & $20-30$ & 57 & 58 \\
& $31-40$ & 24 & 24 \\
& $41-50$ & 11 & 11 \\
\hline Years of practice experience & $>50$ & 7 & 7 \\
& Less than 5 & 71 & 72 \\
& $5-10$ & 15 & 15 \\
& $11-20$ & 8 & 8 \\
\hline Highest Educational Qualification & Over 20 & 5 & 5 \\
& BPharm & 96 & 97 \\
\hline
\end{tabular}


Special Conference Edition, November, 2019

Personal use of herbal supplements

Most of the respondents reported using some type of herbal supplement within the last 12 months $(71 \%)$ and many of them $(90 \%)$, had family members that had ever used these agents too. Herbal supplements were also available in most of the pharmacies where respondents worked (Table 2).

Table 2: Respondents Usage of Herbal Supplements $(n=99)$ Questions

Response n (\%)

Yes No

$90(93 \%) \quad 7(7 \%)$

*Have you ever used herbal supplements before?

$70(71 \%) \quad 28(29 \%)$

*Have you taken any herbal supplements within the past 12 months?

$85(90 \%) \quad 9(10 \%)$

* Have any of your immediate family members (e.g. partner, parents, and siblings) used herbal supplements before?

*Do you stock herbal supplements in your pharmacy?

$83(86 \%) \quad 13(14 \%)$

* Values do not sum up to the total because of missing values

Knowledge of Selected Herbal Supplements

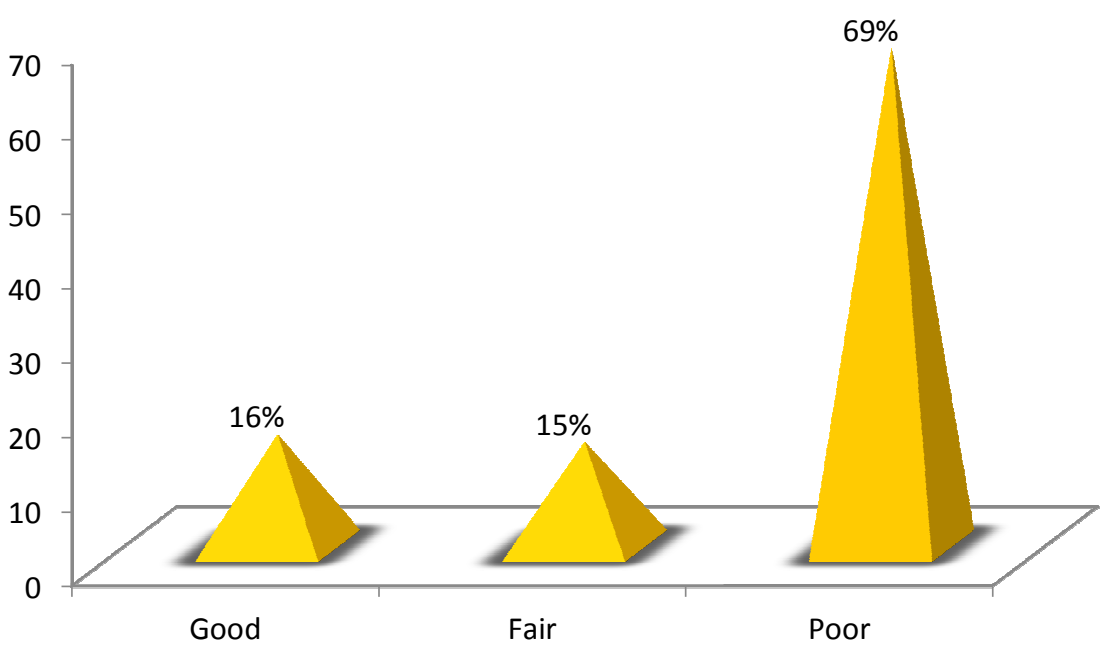

Figure 1: Respondent Knowledge of Indications, Dosing, Side effects \& Drug Interactions of Some Herbal Supplements

Almost $70 \%$ of respondents had poor knowledge regarding the indications, side effects and drug interactions associated with the use of the selected herbal supplements they were examined on (Figure 1).

Respondents Perceptions of Herbal Supplements and Sources of Information on Herbal Supplements

Over $90 \%$ of respondents agreed that herbal supplements are beneficial, and should be integrated into conventional clinical care, however less than half of them believed that these supplements were safe and had fewer side effects than conventional medicines (Table 3 ). Majority (54\%) of respondents also reported that the internet was their major source of information on herbal supplements followed by product leaflets. 
Special Conference Edition, November, 2019

Table 3: Respondents Perceptions of Herbal Supplements $(n=99)$

\begin{tabular}{|c|c|c|c|c|c|}
\hline \multirow[t]{2}{*}{ Statement } & \multicolumn{5}{|c|}{ Response } \\
\hline & $\begin{array}{l}\text { Strongl } \\
\text { y agree }\end{array}$ & Agree & $\begin{array}{l}\text { Neutr } \\
\text { al }\end{array}$ & $\begin{array}{l}\text { Disag } \\
\text { ree }\end{array}$ & $\begin{array}{l}\text { Stro } \\
\text { ngly } \\
\text { disa } \\
\text { gree }\end{array}$ \\
\hline *Clinical care should integrate herbal supplements & $\begin{array}{l}58 \\
(62 \%) \\
42\end{array}$ & $\begin{array}{l}28 \\
(30 \%) \\
47\end{array}$ & $\begin{array}{l}8 \\
(8 \%) \\
4\end{array}$ & 0 & 0 \\
\hline *Herbal supplements have beneficial effects & $(45 \%)$ & $\begin{array}{l}(51 \%) \\
30\end{array}$ & $\begin{array}{l}(4 \%) \\
41\end{array}$ & $\begin{array}{l}0 \\
14\end{array}$ & \\
\hline *Herbal supplements are safe & $8(9 \%)$ & $(32 \%)$ & $(44 \%)$ & $(15 \%)$ & $(1 \%)$ \\
\hline $\begin{array}{l}\text { *Herbal supplements have less side effects than } \\
\text { conventional medicines }\end{array}$ & $\begin{array}{l}13 \\
(14 \%)\end{array}$ & $\begin{array}{l}29 \\
(32 \%)\end{array}$ & $\begin{array}{l}24 \\
(26 \%)\end{array}$ & $\begin{array}{l}20 \\
(22 \%)\end{array}$ & $5 \%$ \\
\hline $\begin{array}{l}\text { *A number of herbal supplements hold promise for the } \\
\text { treatment of symptoms, conditions, and/or diseases }\end{array}$ & 25 & 51 & $\begin{array}{l}16 \\
(\% 17)\end{array}$ & $\begin{array}{l}1 \\
(1 \%)\end{array}$ & 0 \\
\hline $\begin{array}{l}\text { *Patients should inform their pharmacists about their } \\
\text { use of herbal supplements }\end{array}$ & $\begin{array}{l}65 \\
(69 \%)\end{array}$ & 27 & $\begin{array}{l}2 \\
(2 \%)\end{array}$ & 0 & 0 \\
\hline $\begin{array}{l}\text { *Knowledge about herbal supplements is important to } \\
\text { me as a practicing pharmacist }\end{array}$ & $\begin{array}{l}72 \\
(77 \%)\end{array}$ & $\begin{array}{l}17 \\
(18 \%)\end{array}$ & 4 & $\begin{array}{l}1 \\
(1 \%)\end{array}$ & 0 \\
\hline $\begin{array}{l}\text { *It is important to have herbal supplements available } \\
\text { for sale in my pharmacy }\end{array}$ & $\begin{array}{l}34 \\
(36 \%)\end{array}$ & $\begin{array}{l}42 \\
(45 \%)\end{array}$ & $\begin{array}{l}17 \\
(18 \%)\end{array}$ & $\begin{array}{l}1 \\
(1 \%)\end{array}$ & 0 \\
\hline $\begin{array}{l}\text { *Herbal supplements have significant interactions with } \\
\text { conventional medicines }\end{array}$ & 22 & 39 & $\begin{array}{l}27 \\
(29 \%)\end{array}$ & 5 & $\begin{array}{l}1 \\
(1 \%)\end{array}$ \\
\hline
\end{tabular}

* Values do not sum up to the total because of missing values

\section{DISCUSSION}

The aim of this study was to describe the perceptions and knowledge of herbal supplements in community pharmacists practicing within Kaduna state. From our results, almost $70 \%$ of our respondents had poor knowledge about the herbal supplements they were asked about, and over $90 \%$ of them agreed that herbal supplements were beneficial, however less than half of them believed that these supplements were safe and had fewer side effects than conventional medicines.

Most of the respondents in this study were males, aged younger than 40 years and had the Bachelor of Pharmacy degree as their highest educational qualification. This is similar to the findings from similar studies conducted both within and outside the country (Oshikoya et al., 2013; Amorha et al., 2017; Alsayari et al, 2018). Some studies (Bushett et al., 2011; Amorha et al., 2017; have reported fairly high rates (over $70 \%$ ) of herbal supplements usage by community pharmacists and their family members, and this was also seen in this study. This is to be expected, because of the easy accessibility/availability of these agents in community pharmacies.

Poor knowledge of the selected herbal supplements among respondents was observed in this study. This is also in line with findings from earlier studies. Several studies carried out within the country have reported that generally pharmacists have less than optimum knowledge about these agents, especially with respect to dosing, side effects and drug interactions (Adisa and Fakeye, 2006; Amorha et al., 2017; Jimam et al., 2017). Although, studies carried out in other parts of the world (Shraim et al., 2017; Alsayari et al., 2018) have reported that pharmacists are fairly knowledgeable about these agents.

This study, like several others (Amorha et al., 2017; Jimam et al., 2017; Alsayari et al., 2018) established that pharmacists generally perceive herbal supplements as being efficacious or beneficial, with many pharmacists believing that these agents should be incorporated into regular medical care (Amorha et al., 2017; Jimam et al., 2017). Similarly, the pharmacists in this study did not believe that these supplements were totally harmless as evidenced by their responses to the three statements on the safety, side effects profile and drug interaction potential of these agents. Other studies (Oshikoya et al., 2013; Amorha et al., 2017; Jimam et al., 2017; Shraim et al., 2017) have also reported that pharmacists perceive that these supplements may not be completely safe. 
Special Conference Edition, November, 2019

The most common sources of information on herbal supplements used by the pharmacists in this study were the internet and drug information leaflets. This is similar to findings by Bushett et al. (2011), Oshikoya et al. (2013) and Amorha et al. (2017), all of whom have reported that the internet is a popular source of herbal supplement information. However, Oshikoya et al. (2013) and Amorha et al. (2017) also reported that product inserts/leaflets were

\section{REFERENCES}

Adisa, R., \& Fakeye, T. (2006). Assessment of the Knowledge of Community Pharmacists Regarding Common Phytopharmaceuticals Sold in South Western Nigeria. Tropical Journal of Pharmaceutical Research, 5(2), 619-625. doi: $10.4314 /$ tjpr.v5i2.14640

Alsayari, A., Almghaslah, D., Khaled, A., Annadurai, S., Alkhairy, M., \& Alqahtani, $\mathrm{H}$. et al. (2018). Community Pharmacists' Knowledge, Attitudes, and Practice of Herbal Medicines in Asir Region, Kingdom of Saudi Arabia. Evidence-Based Complementary and Alternative Medicine, 2018, 1-7. doi: $10.1155 / 2018 / 1568139$

Amorha, K., Joda, A., Ayogu, E., \& Ubaka, C. (2017). Community pharmacists' assessment of the factors that influence the recommendation of complementary medicines in Lagos State, Nigeria: a pilot study. West African Journal of Pharmacy, 28(1), 71-84.

Auwal, F.I., Dahiru, M.N., Abdu-Aguye, S.N. (2019). Availability and Rationality of Fixed Dose Combinations available in Kaduna, Nigeria. Pharmacy Practice. $17(2) 1470$

Bushett, N., Dickson-Swift, V., Willis, J., \& Wood, P. (2011). Rural Australian community pharmacists' views on complementary and alternative medicine: a pilot study. BMC Complementary and Alternative Medicine, 11, 103. doi: 10.1186/14726882-11-103

Ekor, M. (2013). The growing use of herbal medicines: issues relating to adverse reactions and challenges in monitoring safety. Frontiers in Pharmacology, 4, 177. doi: 10.3389/fphar.2013.00177

Jimam, N., Joseph, B., \& Agba, D. (2017). Pharmacists' knowledge and perceptions about herbal medicines: A case study of Jos and environs. Medical Journal of Dr. D.Y. Patil University, 10(3), 229-233. popularly used by their respondents as sources of information on these supplements.

In conclusion, it may be inferred that community Pharmacists in Kaduna have inadequate knowledge of selected herbal supplements, but hold generally positive perceptions towards their use regardless. There is an urgent need for interventions aimed at improving knowledge of these agents among pharmacists practicing in Kaduna State.

doi:

10.4103/mjdrdypu.mjdrdypu_298_16

Ogbogu, U., \& Necyk, C. (2016). Community Pharmacists' Views and Practices Regarding Natural Health Products Sold in Community Pharmacies. PLOS ONE, 11(9), e0163450. doi: 10.1371/journal.pone. 0163450

Oshikoya, K., Oreagba, I., Ogunleye, O., Oluwa, R., Senbanjo, I., \& Olayemi, S. (2013). Herbal medicines supplied by community pharmacies in Lagos, Nigeria: pharmacists' knowledge. Pharmacy Practice, 11(4), 219-227. doi: 10.4321/s1886-36552013000400007

Shraim, N., Shawahna, R., Sorady, M., Aiesh, B., Alashqar, G., \& Jitan, R. et al. (2017). Community pharmacists' knowledge, practices and beliefs about complementary and alternative medicine in Palestine: a cross-sectional study. BMC Complementary and Alternative Medicine, 17, 429. doi: 10.1186/s12906-017-1940-8

Terrie, Y. (2012). Using Herbal Supplements Safely. Pharmacy Times. Retrieved from https://www.pharmacytimes.com/public ations/issue/2012/march2012

Wegener, T. (2017). Patterns and Trends in the Use of Herbal Products, Herbal Medicine and Herbal Medicinal Products. International Journal of Complementary \& Alternative Medicine, $9(6), \quad 00317 . \quad$ doi: 10.15406/ijcam.2017.09.00317 